\title{
Sustainability Centres and Fit: How Centres Work to Integrate Sustainability Within Business Schools
}

\author{
Rieneke Slager ${ }^{1} \cdot$ Sareh Pouryousefi ${ }^{2} \cdot$ Jeremy Moon $^{3} \cdot$ Ethan D. Schoolman $^{4}$
}

Received: 9 May 2017 / Accepted: 26 June 2018 / Published online: 11 July 2018

(c) The Author(s) 2018

\begin{abstract}
For nearly as long as the topic of sustainable business has been taught and researched in business schools, proponents have warned about barriers to genuine integration in business school practices. This article examines how academic sustainability centres try to overcome barriers to integration by achieving technical, cultural and political fit with their environment (Ansari et al. in Acad Manag Rev 35(1):67-92; Ansari et al., Academy of Management Review 35(1):67-92, 2010). Based on survey and interview data, we theorise that technical, cultural and political fit are intricately related, and that these interrelations involve legitimacy, resources and collaboration effects. Our findings about sustainability centres offer novel insights on integrating sustainable business education given the interrelated nature of different types of fit and misfit. We further contribute to the literature on fit by highlighting that incompatibility between strategies to achieve different types of fit may act as a source of dynamism.
\end{abstract}

Keywords Sustainable business education $\cdot$ Academic centres $\cdot$ Fit

\section{Introduction}

In a world gripped by environmental problems, financial crises and corporate scandals, modern organisations routinely encounter sustainability issues in day-to-day business activities. In recent years, business schools have come under scrutiny for their failure to instil a sufficiently deep sense of responsibility and to prepare graduates for the sustainability

Rieneke Slager

C.H.Slager@rug.nl

Sareh Pouryousefi

Sareh.Pouryousefi@nottingham.ac.uk

Jeremy Moon

jmo.ikl@cbs.dk

Ethan D. Schoolman

ethan.schoolman@rutgers.edu

1 University of Groningen, Nettelbosje 2, 9747 AE Groningen, Netherlands

2 Nottingham University Business School, Wollaton Road, Nottingham NG8 1BB, UK

3 Copenhagen Business School, Porcelaenshaven 18A, 2000 Frederiksberg, Denmark

4 Rutgers, The State University of New Jersey, 55 Dudley Road, New Brunswick, NJ 08901-8520, USA challenges of the modern business environment. In response to external stakeholder pressure on business schools to focus on sustainability education (Matten and Moon 2004; PRME 2017a; Rasche et al. 2013), a growing number of schools are creating academic centres, which focus explicitly on promoting sustainable business education (ABIS and EFMD 2013). We use the term sustainable business education as a broad categorisation for efforts to embed ethics, corporate social responsibility and sustainability ${ }^{1}$ in business school education (Godemann et al. 2014; PRME 2015). For the purpose of this article, we take 'education' to encompass teaching, research and engagement activities - teaching in higher education is typically informed by research, which in turn is disseminated and evaluated through engagement activities.

The design of sustainable business education varies considerably across business schools (Christensen et al. 2007; Moon and Orlitzky 2011; Matten and Moon 2004). Consider curriculum development, a longstanding area of research in the literature on sustainable business education. Sustainability topics have been addressed through individual stand-alone courses, degree specialisations and

\footnotetext{
${ }^{1}$ Although the terms 'ethics', 'corporate social responsibility', and 'sustainability' clearly involve distinctive conceptual features, we treat them here as a single cluster under the title of 'sustainability' as is increasingly common in the field of management education and learning.
} 
electives, and built into the core curriculum (Rusinko 2010; Snelson-Powell et al. 2016). Such diversity in the adoption of sustainable business education can be explained in part through the various strategic, structural and cultural barriers faced by proponents in different settings (Solitander et al. 2012). For example, research shows that the legitimacy of sustainability topics is often disputed (Hommel and Thomas 2014), and that sustainability is routinely misunderstood and underappreciated among business school educators (Jamali and Abdallah 2015). And despite the pressure from accreditation agencies to embed sustainability across business school programmes, clear templates for the design and implementation of sustainability education are hard to come by (Rasche and Gilbert 2015). These barriers may hamper substantive integration of sustainability topics within business school education (Rasche and Gilbert 2015; SnelsonPowell et al. 2016). According to a recent survey, only $42 \%$ of deans and $37 \%$ of faculty believe that business schools have formulated an appropriate response to the integration of sustainability issues (ABIS \& EFMD 2013, p. 1). Whilst recent research highlights some of the barriers to long-term integration of sustainable business education, we still know little about how proponents are working to achieve the goal of embedding sustainability into business education. Specifically, little is known about how advocates may succeed in establishing fit between sustainable business education practices and their existing internal environment. Practices that fit the organisational environment are more likely to be durable and successful (Andrews 1971; Zajac et al. 2000). Ansari et al. (2010) theorise that organisations adapt practices in order to achieve technical, cultural and political fit within internal organisational environments. In the context of sustainable business education, we believe that such a dynamic conceptualisation of fit is insightful by emphasising the ways in which changes in one type of fit can lead to or inhibit changes in another. This approach to the study of fit has the additional advantage of calling attention to two further issues in the integration of sustainable business education, which thus far have remained theoretically underdeveloped. First, since the political, cultural and technical elements surrounding sustainability integration can differ and even contradict one other, we need to understand each element separately, before attending to the dynamic interplay between different types of fit. Second, some researchers have suggested that purposeful misfit may lead to goal achievement in turbulent and contested environments (Voelpel et al. 2006). Thus, in the sustainable business education context, purposeful misfit may at times be a superior strategy, and deserves attention alongside fit.

Our research question is how do sustainability centres achieve technical, cultural and political fit between sustainable business education practices and their internal environment? We focus on academic sustainability centres as key focal points for the promotion of sustainable business education. The existence of such centres 'implies long-term institutional support as well as legitimacy and validation for sustainable business education' (Christensen et al. 2007, p. 352). As such they present a 'best case' scenario to study how fit may be achieved in pursuit of the integration of sustainable business education. Based on survey and interview data, we find that centres based in business schools that are prominent in the field of sustainability have deployed a wide range of strategies to achieve technical, cultural or political fit. We argue that the interconnections between the three types of fit can be understood as involving legitimacy, resources and collaboration effects. Our findings suggest that when the three types of fit exist simultaneously, these effects can be harnessed to achieve integration in the long term, whilst a lack of cultural and/or technical fit may hamper both substantive integration of sustainability practices as well as their perceived long-term viability.

We contribute to the literature on the integration of sustainable business education by highlighting the interconnected nature of the three types of fit. Our findings suggest that each type of fit, if achieved, supports the others in unique and specific ways. Conversely, in the presence of one type of misfit, other types of fit may not be achievable or even desirable. The desirability of outcomes associated with different types of fit and misfit - and different combinations thereof-deserves critical attention by sustainability proponents, given widespread variation in the technical, cultural and political organisational environments in business schools. We also contribute to the literature on fit (Ansari et al. 2010,2014) by examining the strategies that can be employed to achieve technical, cultural and political fit. Our analysis of the work of sustainability centres sheds light on a key source of dynamism stemming from the interrelations between the three types of fit, whereby the choice of strategy deployed to achieve one type of fit has implications for the possibility of achieving the other types of fit.

The paper is structured as follows. The next section reviews the literature on fit in the context of sustainable business education. The "Methods" section describes the research context, data collection and analysis methods. The "Findings" section is divided into three parts: part (i) describes general trends regarding the role and purpose of sustainability centres. Part (ii) examines the centres' strategies to achieve technical, cultural and political fit. Part (iii) describes the interconnections between the different types of fit. The paper concludes with a discussion section outlining the contributions of the study to the literature and its implications for research and practice, including a critical discussion of the possible strategies for centres to move 'beyond fit' to achieve more radical change for sustainability goals. 


\section{Fit in the Context of Sustainable Business Education}

A variety of theoretical traditions, including strategic management (Venkatraman 1989; Andrews 1971) and contingency theory (Drazin and van de Ven 1985), have examined fit between an organisation's strategy or structure on the one hand, and the organisation's environment on the other. In strategy, the idea of congruence or alignment between strategy and environment is thought-explicitly or implicitly - to have a positive effect on performance (Miles and Snow 1978; Kaplan and Norton 2006). It should be noted that whilst the consensus has pointed towards the positive effects of fit on performance, dissenting voices can be found. For example, Voelpel et al. (2006) argue that in response to modern turbulent environments, misfit can present a strategic response that may be intentionally drawn upon in organisations seeking growth and innovation. In a similar vein, as conflicting demands are being placed on organisations by stakeholders, Brunsson (2002) highlights misalignment between strategy and some stakeholder demands as a necessary element for businesses to remain in operation.

Research in strategic management has highlighted that the concept of fit should be treated as multidimensional and dynamic (Zajac et al. 2000; Venkatraman 1989). Ansari et al.'s (2010) theorisation of technical, cultural and political fit builds on this tradition to examine how new practices can be made to fit within the internal environments of organisations. They argue that technical, cultural and political factors will determine the degree of fit between organisational characteristics and new practices that are implemented by the organisation. Because Ansari et al. (2010) focus on the consequences of misfit for subsequent practice adaption, they have not theorised in detail the complex intra-organisational work that may be needed to achieve fit. In other words, the question of how fit is achieved between new practices and an organisation's internal environment has not yet been addressed in a comprehensive way. Ansari et al.'s (2010) framework mirrors to some degree concepts developed in a separate, but parallel literature on institutional work (Lawrence and Suddaby 2006; Perkmann and Spicer 2008). This literature examines various types of strategy that are employed by actors within an organisation to institutionalise new practices, so that these practices become acceptable and taken for granted.

Given our goal of examining how centres work towards the integration of sustainable business education through fit/misfit strategies, we will draw on both the fit and the institutional work literatures. Worries remain that sustainability has entered but not yet become embedded into mainstream business education (PRME 2015; Starik et al. 2010). We argue that a multidimensional conceptualisation of fit will enable us to respond to recent calls to examine the dynamics that guide business schools' efforts towards sustainability integration (e.g. Hommel and Thomas 2014). Specifically, we analyse three types of fit:

Technical fit is defined as the alignment with current organisational structures, capabilities and knowledge. In the context of sustainable business education, barriers to technical fit stem from the interdisciplinary nature of the subject as well as challenges in curriculum (re)design. With regards to the challenges posed by interdisciplinarity, various studies show that the existing structures in business schools do not easily accommodate an interdisciplinary subject such as sustainability, given that staff might be trained in a narrow discipline (Benn and Martin 2010) or are unfamiliar with specific recommended sustainability teaching styles (Akrivou and Bradbury-Huang 2015; Benn and Martin 2010; Maloni et al. 2012; Sharma and Hart 2014). These challenges aggravate structural problems in curriculum re-(design); leading to a situation where sustainability topics are often offered in elective or specialised courses rather than as part of the core curriculum (Rasche and Gilbert 2015).

Whereas Ansari et al. $(2010,2014)$ emphasise fit with existing technologies, the literature on institutional work provides a richer conceptualisation of the kind of work that is needed to achieve technical fit. For example, technical fit may involve cognitive types of work, such as the development of templates, procedures, manuals or tools that serve to aid alignment and integration (Lawrence and Suddaby 2006; Perkmann and Spicer 2008; Suddaby and Greenwood 2001). Moreover, achieving technical fit is likely to include what institutional theorists refer to as 'bricolage': creatively constructing new structures and templates from a mixture of new and existing elements (Lawrence and Suddaby 2006, p. 229).

Cultural fit is defined as alignment with the cultural values, beliefs and practices of organisational members (Ansari et al. 2010, p. 78). In the context of sustainable business education, resistance from organisational members has been identified as one of the barriers to sustainability integration, since the normative characteristics of sustainable business education may be incompatible with norms held by other business school constituents (Rasche and Gilbert 2015; Solitander et al. 2012; Benn and Dunphy 2009). As pointed out by a number of (critical) studies, the dominant belief in business schools is influenced by a neo-liberal ideology, which does not accommodate a holistic perspective on sustainability (Banerjee 2011; Akrivou and Bradbury-Huang 2015; Giacalone and Thompson 2006). A lack of cultural fit in business school may thus stem from clashes in core beliefs and values underpinning business education held by staff members across a range of disciplinary groups. Greater cultural 
fit is achieved when there is congruence between the inherent norms and values of a practice such as sustainable business education, and the existing values and beliefs of organisational members. This entails framing practices in such a way that they are tolerated at a minimum, and in a best case scenario actively participated in (Canato et al. 2013). Framing can also involve giving scope to the appropriate roles and responsibilities of those involved (Ansari et al. 2010, p. 78). Cultural work often involves cooperative processes that emphasise building communities that share similar norms and values (Lawrence and Suddaby 2006, p. 228). In order to counteract cultural misfit, in the long-run, changes may be necessary to the broader organisational culture (Canato et al. 2013), so that both the practices that are being promoted and the environment in which they are being received are likely to change in the course of integration.

Political fit entails alignment with the agendas and interests of key organisational actors. This perspective recognises that organisations consist of individuals and groups that have evolving and diverging interests and resources (Weber and Weager 2017). In the context of sustainable business education, substantive integration depends in part on internal organisational politics and the allocations of power and resources (Solitander et al. 2012). Barriers to political fit may involve reported lack of interest from senior school leaders (Doherty et al. 2015; Sharma and Hart 2014). Alternatively political fit may not be achieved due to conflicting or vague demands placed on deans by external actors such as accreditation agencies. Organisations such as the Principles for Responsible Management Education (PRME) initiative, which seek to promote sustainable business education, do not provide a clear template for its design and implementation (Rasche and Gilbert 2015). Achieving political fit typically involves capturing the interests, power structures and agendas of individuals and dominant coalitions in an organisation (Ansari et al. 2014, p. 1316). Such political work can involve attempts at mobilising support through advocacy and social suasion in order to convince powerful factions of the value of new practices. It can also involve the design of rules that guide who gets to partake in the new practices and which parties get to share associated resources (Perkmann and Spicer 2008; Lawrence and Suddaby 2006). Whereas cultural work involves framing practices in such a way that they appeal to a wider set of organisational members, political work entails social persuasion directed at a limited set of powerful organisational actors (Perkmann and Spicer 2008). According to this stance, achieving political fit is likely to be the result of a top-down process that depends on the authority of dominant organisational actors and the resources that they control. ${ }^{2}$

\footnotetext{
2 A comprehensive conception of organisational political interactions involves reviewing a vast multi-disciplinary literature. In this article, we limit our focus to a simplified conception derived from standard approaches in the strategy and management literatures on fit and insti-
}

\section{Methods}

\section{Research Context}

Sustainability centres carry out collaborative research, attempt to embed sustainability in the core business school curricula and engage a range of stakeholders inside and outside the university (PRME 2015). Since the 1990s, more than 200 applied academic sustainability centres have been developed around the world, and this number continues to grow (Starik et al. 2010; Godemann et al. 2011). ${ }^{3}$ This growth mirrors the growth of academic centres in different subject areas within business schools, including entrepreneurship (Friga et al. 2003; Mangematin and Baden-Fuller 2008; Zahra et al. 2011). One-fifth of the business schools which responded to Matten and Moon's survey (2004) had a dedicated CSR research centre or institute. In a follow-up survey by Orlitzky and Moon (2010), 58\% of respondents had a dedicated centre for CSR research. The latest survey data reveal that the highest level of commitment to sustainable business education by business schools takes place within sustainability-focused institutes and centres (ABIS and EFMD 2013, pp. 27-28). Academic centres represent a signalling device for a school's mission and strategy, and can represent significant investment in resources (Zahra et al. 2011). As such, centres represent a 'best case' for examining how fit may be achieved in the context of sustainability business education.

In order to answer our research question, a two-stage research design was employed. The first stage consisted of a short survey, and the second stage of in-depth interviews with the directors of 10 leading sustainability centres. Whilst existing surveys provide some trend data about the growth of sustainability centres, they cannot provide insight into the activities carried out within these centres. The aim of our survey was to categorise the main activities of sustainability centres as they carry out their mission, and to gain an understanding about the activities that take priority in centres' day-to-day operations. The aim of the interviews was to get an in-depth sense of how prominent centres had developed over time, and the strategies employed in achieving fit with the environment in which they operated.

\footnotetext{
Footnote 2 (continued)

tutional work. We drew on these same literatures to make a distinction between cultural and political elements of organisational work. Nonetheless, we recognise that the boundaries between the political and cultural realms may well be more fluid than this distinction suggests, especially outside the literature on strategic management.

${ }^{3}$ Most though not all these centres and institutes are based in business schools.
} 
Table 1 Interview participants

\begin{tabular}{lllll}
\hline Participant & Region & $\begin{array}{l}\text { PRME signa- } \\
\text { tory }\end{array}$ & $\begin{array}{l}\text { 2015 FT ranking } \\
\text { school }\end{array}$ & Accreditation \\
\hline 1 & North America & Y & Top 100 & EQUIS \\
2 & North America & Y & & AMBA, EQUIS \\
3 & North America & N & Top 50 & AACSB \\
4 & North America & N & Top 10 & AACSB \\
5 & North America & N & Top 10 & AACSB \\
6 & Western Europe & Y & & AMBA, EQUIS \\
7 & Western Europe & Y & & AMBA \\
8 & Western Europe & Y & Top 100 & AACSB, EQUIS \\
9 & Western Europe & Y & & AACSB, AMBA, EQUIS \\
10 & Western Europe & Y & Top 50 & AACSB, AMBA, EQUIS \\
\hline
\end{tabular}

EQUIS European quality improvement system is an international system of assessment and accreditation of higher education institutions in management and business administration run by the European Foundation for Management Development; $A M B A$ association of MBAs; $A A C S B$ association to advance collegiate schools of business

\section{Data Collection}

We define a sustainability centre as an organisation within a university or a business school focused on developing and practising sustainability research, teaching, knowledge dissemination and engagement. We identified 129 sustainability centres through examining university webpages and by consulting a list of centres compiled by the Network for Business Sustainability (NBS). ${ }^{4}$ Our survey was conducted online, and the recipients were e-mailed no more than three times over a period of 5 months. The initial e-mail response revealed a fairly low response rate of 25 completed surveys. To increase the response rate, follow-up phone-calls were conducted; this increased the total responses to $60 \mathrm{com}$ pleted surveys. After removing incomplete survey responses, the total completed surveys numbered 58 , a response rate of 45\%. 64\% of respondents were based in North America, 19\% in Europe and 17\% in other regions (including Asia, Africa and the Middle East). ${ }^{5}$ The survey contained nine structured questions regarding founding date, source of origin, purpose of the centre, centre activities, staffing and disciplinary focus (see Appendix).

The survey included a request for a follow-up interview; of those that responded favourably to the request, ten directors were purposively selected. Table 1 lists the details of the

\footnotetext{
${ }^{4}$ NBS, launched in 2005, is a non-profit network of academics and business leaders that focuses on management practice and research in the area of sustainability.

5 This response rate reflects the regional distribution of the 129 centres that received our survey: a large number of centres (88) are based in North America relative to the rest of the world. A calculation of the response rate of recipients per region shows a more equal distribution of responses with Europe and North America both around the $40 \%$ response rate.
}

interview participants. Five participants represent centres in North America and another five represent centres in Western Europe. All participants headed centres located within business schools that were either free-standing or part of a larger university. In two cases, the centres headed by participants also served as the major node of an organised network of centres spanning multiple business schools. These latter two participants were able to provide background information regarding general trends concerning centres, such as common barriers to integration. ${ }^{6}$ Seven of our interviewees represented centres that were signatories to the Principles for Responsible Management Education (PRME) initiative, and all participants stemmed from institutions that are well known for their commitments in the area of sustainable business education. Where available, we included the latest PRME report of the respective signatories in the analysis.

We developed a semi-structured interview guide with a set of open-ended questions based on the results of the survey. Specifically, we asked interview participants about their research and teaching activities, their engagement with stakeholders and the challenges faced in the development of their centre. We also asked them to describe day-to-day operations, as well as major developments and changes in their environment (at the business school, college and university levels). Finally, we elicited their perspectives on the future of sustainability centres. The second and fourth author conducted all interviews either face to face or via Skype; all

\footnotetext{
${ }^{6}$ The initial sample decision for these two cases was made based on the prominence of the (intra-institutional) centre itself, but during the interview the significance of the cross-institutional networks became clear and was discussed in-depth, for example regarding the barriers to integration experienced by members of the network. In both cases the network's international membership contains sustainability centres situated (mainly) within business schools.
} 
Table 2 Technical, political and cultural fit of sustainability centres in business schools

\begin{tabular}{|c|c|c|c|}
\hline Type of fit & Technical & Cultural & Political \\
\hline Definition & $\begin{array}{l}\text { Alignment with current organisational } \\
\text { structures, capabilities and knowledge }\end{array}$ & $\begin{array}{l}\text { Alignment with the cultural values, } \\
\text { beliefs and practices of organisational } \\
\text { members }\end{array}$ & $\begin{array}{l}\text { Alignment with agenda and interests of } \\
\text { key organisational actors }\end{array}$ \\
\hline Evidenced by & $\begin{array}{l}\text { Functional integration in existing or new } \\
\text { structures }\end{array}$ & $\begin{array}{l}\text { Buy-in from members that do not have a } \\
\text { direct stake or a technical role }\end{array}$ & Support from key organisational actors \\
\hline Achieved through & $\begin{array}{l}\text { Creation of new structures (narrow fit); } \\
\text { integration into core curriculum \& } \\
\text { engagement as a key capability (broad } \\
\text { fit) }\end{array}$ & $\begin{array}{l}\text { Overcoming resistance through social } \\
\text { suasion; inclusive framing of activities } \\
\text { and roles }\end{array}$ & $\begin{array}{l}\text { Positioning in line with School/Univer- } \\
\text { sity strengths; developing a sustain- } \\
\text { ability brand }\end{array}$ \\
\hline Centre 2 & $*$ & $* *$ & $* *$ \\
\hline Centre 3 & $*$ & & $*$ \\
\hline Centre 4 & & & $*$ \\
\hline Centre 5 & $*$ & $* *$ & $*$ \\
\hline Centre 6 & $*$ & $*$ & $* *$ \\
\hline Centre 7 & $*$ & $* *$ & $* *$ \\
\hline Centre 8 & & & $* *$ \\
\hline Centre $9^{a}$ & $*$ & $*$ & $* *$ \\
\hline
\end{tabular}

*Evidence suggests fit is being pursued

**Evidence suggests fit is established

${ }^{a}$ Two of our interviews were conducted with participants that headed centres which had developed formal networks of centres that spanned across multiple business schools. Whilst their insights served to confirm findings from the other interviews regarding barriers to integration, they provided less evidence with regards to fit with the internal environment and therefore they are not included here

interviews were recorded and transcribed. Interviews lasted between 45 and $70 \mathrm{~min}$, and $55 \mathrm{~min}$ on average.

\section{Data Analysis}

The survey was conducted via an online survey platform, and the results were compiled in Excel. Analysis of the survey data focused on the descriptive elements of centres (i.e. their main activities and disciplinary focus). Analysis of the interviews and PRME reports combined inductive and abductive elements, conducted with the help of NVivo qualitative analysis software. The coding was developed and applied through continuing discussion between the first and second author. The preliminary results of the coding process were then discussed further with all authors. First, raw codes were developed based on the interview transcripts and reports, with codes closely matching interview participants' phrasing such as 'the life of this place', 'convincing colleagues', 'working yourself out of your job'. We were particularly interested in three kinds of descriptions: (a) the characteristics of sustainable business education (e.g. interdisciplinary nature of the sustainability topic); (b) strategies employed to develop the centre and (c) stories regarding 'fitting in', overcoming resistance and achieving legitimacy.

In the second step of analysis, we went back to the literature on sustainable business education and noted that the problem of integration has not been addressed from the perspective of fit. We then examined the interview data again, paying close attention to different types of fit and the work done by centres to address fit whilst overcoming barriers to integration. We employed a process of 'constant comparison' (Charmaz 2006; Glaser and Strauss 1967) between theory and data to move from the raw codes to the secondorder constructs of technical, cultural and political fit. This step, which included the writing of memos for discussion and analysis, led to the grouping of evidence under the categories of technical, cultural and political fit (see top half of Table 2). Equally, codes related to lack of fit or misfit, such as 'resistance from colleagues' were coded for each of the three categories. For example, political fit was evidenced by the degree of support from key organisational actors, the receipt of which was included among others by codes related to 'support from the Dean', and codes related to funding and resources. We then examined common strategies to achieve political fit, which included positioning in line with the strength of the school or university, and developing a sustainability brand. We re-examined each interview to analyse the extent to which the centre head had experienced fit or misfit in each category (see bottom half of Table 2). In a final step, we explored the interconnections between the three categories of fit, by examining the evidence in each category of fit, and investigating to what extent the other two categories of fit had preceded or followed it. By creating analysis tables in the software, we examined how the three 
Fig. 1 The recursive interconnections between the three types of fit of sustainability centres

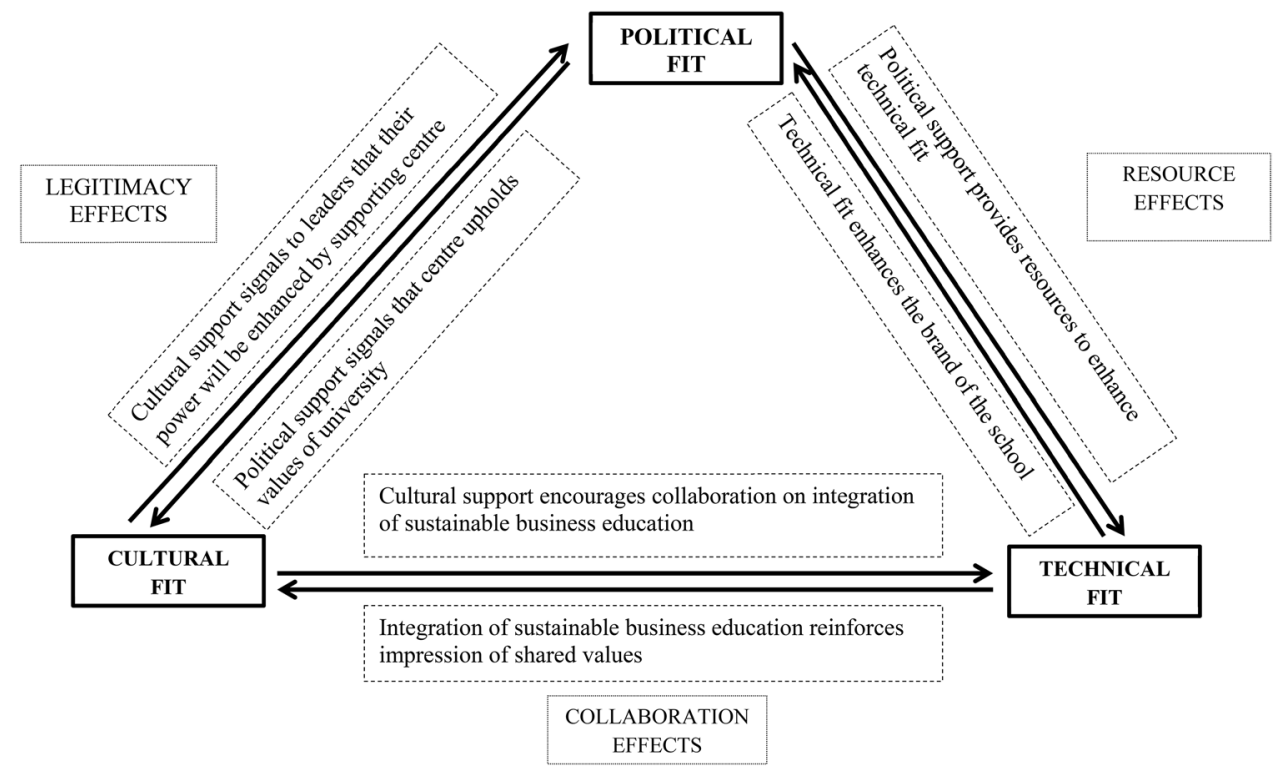

categories of fit overlapped, and from this we induced our framework related to the interconnections between the three types of fit (see Fig. 1).

\section{Findings}

The Findings section is divided into three sections. The first section describes the main activities and disciplinary focus of the sustainability centres that were surveyed. The second section draws on interview data to examine the three types of fit and the work that is being carried out, or purposefully avoided, by centres in order to achieve fit. The third and final section discusses the interconnections between the three types of fit.

\section{Main Activities of Centres}

Sustainability centres, like centres in higher education in general, do not have 'a set of rigid characteristics' (Etzkowitz and Kemelgor 1998, p. 271; Stahler and Tash 1994). Our survey identified several trends in the operation and development of sustainability centres globally. Just over half of the centres $(53 \%)$ in the survey were established in or after 2007 (the year the PRME was developed), whilst 2 centres were established as early as 1985 . The survey results suggest that the purpose of the centres tends to be multi-functional, with research, teaching and outreach to external stakeholders all identified as key activities. Outreach is generally considered equally as important as research and teaching. Respondents were asked to rank their centre's purpose on a 5-point scale ranging from not important (1) to extremely important (5), with multiple options possible. 'Research' achieved the highest average rating (4.22); followed by 'outreach and external engagement' (4.2) and 'teaching and student experience' (4.05). Given the possibility of centres adapting or developing their founding purpose, a question was also asked concerning their current core and secondary activities. The most common core activities mentioned include dissemination of information (76\% of respondents), academic research (73\%) and network building (66\%). In terms of secondary activities, the most common activities were consultancy (40\%) and provision of internships (31\%) and research focused on policy or practitioner topics (33\%). This shows that current achievements in centres reflect a strong blend of core academic activities with dissemination, networking building and general engagement with practice.

The majority of centres $(67 \%)$ indicate that they have a multidisciplinary focus in their activities related to research, teaching and outreach. Other common disciplinary focuses mentioned were sustainability $(67 \%)$ and management (59\%). Notably, $33 \%$ of respondents indicate a transdisciplinary focus, which transgresses disciplinary paradigms altogether and involves scholarly engagement with practice in an effort to solve real-world problems that have practical and social significance (Hadorn et al. 2008). These characteristics reflect the multidisciplinary nature of sustainability centres, as well as their strong engagement with practice.

\section{Three Types of Fit}

The majority of centres seek to promote sustainable business education to a critical mass of students and staff. In order to achieve this goal, most centres we studied seek to 'fit in' with their internal environment. In a few cases, centres are content to exist more independently from general 
management education, especially if doing so enables them to provide a critical or interdisciplinary perspective in their business school. Even in these cases, it is recognised that some degree of fit with the rest of the school and/or the university needs to be in place in order to ensure the viability of the centre. Table 2 highlights the categories of fit for the centres as evidenced in the interview and report data.

\section{Technical Fit}

Technical fit relates to alignment with current organisational structures, capabilities and knowledge. Technical fit is evidenced by the functional integration of the sustainability topic into existing structures or clearly defined new structures. For example, in terms of teaching, sustainability can be addressed through existing structures as a new topic or case in the existing curriculum. It can also be addressed through new structures such as a new course or programme (Rusinko 2010, p. 509). Rasche et al. (2013) have pointed out that although many more sustainability courses are offered, the majority of these are electives and not integrated into the core curriculum offer. We find that incorporating sustainability into the core curriculum is a key area of focus for the majority of centres: 'it's the curriculum work that I think is the sign of success' (Centre head, centre no 1). If technical fit is narrow, the devised structures for teaching may be clearly defined and functioning, but they stand somewhat apart from the rest of curriculum.

In ten years we have seen this huge uptake of students who are interested in sort of straddling that business and society line. And there aren't, other than us, there just aren't places within the school for students to find support to learn more about it and skill up professionally for it, to make the contacts that they need. (Centre Head, centre no 4).

Such narrowly defined, stand-alone courses may lead to a lack of integration of sustainable business education. We find that a broader technical fit means offering electives as well as integration into the core curriculum, to provide students an opportunity to engage with the topic according to their interest.

So what we've come to understand on the student front is that we can create the sort of concentric circles of engagement for students where the outer ring is everyone who comes through the School should get some dose of sustainability through infusion into core curriculum. If they want to go a little deeper they can come get a free lunch at this weekly lunch series or get involved with one of the clubs. If they want to go deeper they'll take an elective class and if they want to go deeper they can pursue the certificate. (Centre head, centre no 5).

Most centres also identify engagement as an important role, as they are often active in reaching out and engaging with stakeholders in the external environment, such as NGOs, businesses and government. The survey results show that engagement and outreach are considered almost as important as research and teaching activities for nearly all centres. Engagement with practice is conceptualised as part of the 'raison d'être' of being a centre that focuses on sustainability topics:

We are doing interesting stuff that has relevance. I think it would be, I don't know, almost morally corrupt to just keep it to ourselves. We've got something to say, I think we should be out there saying it (Centre Head, centre no 7).

It seems that a clear template for sustainable business education has not appeared with regards to teaching and curriculum design, but a stronger consensus has been arrived at regarding the roles and responsibilities of centres in engagement activities. According to this stance, whilst centre staff might be able to continue research and teaching activities in the absence of the institutional and administrative support of centres, it would be impossible to carry out ongoing engagement activities without a sustainability centre. Engagement activities are in principle aimed at individuals, groups and institutions outside the business school and university environment. But it is the very externally oriented nature of engagement work that enables centres, by playing a distinctive role as providers of high-profile engagement around sustainability, to gain visibility and recognition within their internal environment. This is especially so given the growing importance of research impact and socially beneficial objectives to universities at large.

\section{Cultural Fit}

Cultural fit involves alignment with the values, beliefs and identity of organisational members. Achieving cultural fit requires buy-in from members that do not have a direct technical role (Perkmann and Spicer 2008, p. 818) in sustainable business education, but that need to be convinced about the value of such practices in order to provide a wider support platform. One strategy for achieving greater cultural fit that is often employed by centres is to spend considerable effort on overcoming resistance among colleagues:

We managed to slowly-slowly convince a lot of resistant, hesitant study programme managers. You know, boost whatever they're doing in this area, helping them to do so and inspiring them and so on. So it's a slow process. ... and I think we should remember also you 
know, for the many years a lot of colleagues thought CSR has got nothing to do with business. (Centre Head, centre no 9).

There are certain people in the school who never quite see Corporate Social Responsibility or sustainability as pressing issues for business or indeed for society. I suppose if every member of the school was persuaded on these things you wouldn't need a centre. I think to some extent a centre is a point of expertise but it's also a sort of internal agitator. (Centre Head, centre no 6).

In order to achieve greater buy-in and overcome resistance, the framing employed by some of centres (e.g. centre $1,2,6,7,9)$ is very inclusive and flexible. There is very little emphasis on a clear definition of sustainable business education, or the demarcation of 'turf' with respect to roles and responsibilities. Definitions of terms such as 'sustainability' and 'CSR' are often purposefully not predetermined and research themes are loosely interpreted to be inclusive towards colleagues with related research interests. Quite a few of our interview participants could not clearly identify which organisational members were affiliated with their centre for example, and were open to welcoming anyone who is interested in sustainability topics.

The legitimacy of the centre is partly bound up in who's involved in it but also, much more so, in terms of what you actually do. And if you can do things that people find valuable to their work, then you're more likely to be seen as legitimate. If the stuff that you do as a centre is not seen as relevant or interesting, or anything that people will get involved in, then I think that's where it starts to lose its legitimacy as something that represents the school rather than represents a particular group of people. (Centre Head, centre no 2).

[Our research themes are defined] partly due to the people we've recruited but also other members of the department sort of verging towards sustainability as an issue and being comfortable to hang the work they do, sort of hang it on a sustainability label (Centre head, centre no 7).

In other centres, framing around sustainable business education is more explicit, taking for example a critical perspective or a perspective informed by an interdisciplinary focus. This leads to a clearer identification of who is involved with sustainable business education, but also, crucially, a degree of isolation. For example, a longstanding centre historically framed its purpose around business ethics, with an emphasis on criticising and questioning the role of business in society. The centre director describes the centre's functioning in these years as a 'beautiful island' (Centre Head, Centre no 8) amidst the more mainstream business school departments, whilst not being interested in close cooperation or in-depth integration of the sustainability topic across the business school. A narrowly defined framing of the themes, perspectives or disciplines employed to study sustainability can lead to strong identification of staff members with a centre, whilst at the same time alienating organisational constituents in the wider internal environment.

\section{Political Fit}

Political fit entails alignment with the agendas and interests of key organisational actors. A higher degree of political fit is evidenced by the support of powerful members in the internal environment, which can be used to promote sustainable business education practices. Deans or vice-chancellors often play an important role in the inception of the centre, and continue to be important over the lifespan of the centre. Indeed, signatories of the PRME need to provide evidence of the support 'by the highest executive of the organisation' (PRME 2017) in their reporting on implementation of the principles. Once the support of powerful actors is secured, political fit can also ensure that resources (e.g. funding, staff recruitment, offices, administrative support) are provided to support the promotion of sustainable business education. These resources may be used to support teaching activities or provide funding for research and engagement activities on sustainability topics. If these resources are shared with colleagues outside the centre, this may promote more attention to sustainability topics and aid integration of sustainable business education, including research activities:

In trying to normalise us and integrate us we offered some of our gold to the colleagues by offering a research grant. Minor little research grants for other people outside the centre who wanted to engage in CSR research ... Again it was a way of trying to make the centre a creature of the School rather than something hanging off the edge which would have been disastrous (Centre Head, centre no 6).

We found an important strategy for achieving political fit that entails the careful positioning of the centre so that it is seen to strengthen the mission of the school or university in which it operates. For example, in a business school that distinguishes itself from competitors through its international campuses, the activities of the sustainability centre are explicitly international in focus, offering scholarships to international students, for example, and embedding international perspectives into sustainability research. In another school where innovation is a key subject, 'innovation for sustainability' is the differentiating theme. Building on key existing themes and orientations within the internal environment not only differentiates the activities of sustainability centres from competitors, it also 
serves to align sustainable business education with the existing internal interests and agendas that have political significance.

You are part of the environment you live in, so you will reflect the school that you're a part of and you will reflect the interests of the director and the staff (Centre Head, centre no 3).

Another, related strategy that leading centres use to achieve political fit is the exploitation of the external demands for sustainable business education to frame the contribution of centres to the overall brand of their school. For example, initiatives such as PRME, backed by the United Nations, help to place sustainability on the agenda of senior management in business schools. In schools where sustainability centres were established before these changes in the external environment took place, the activities of sustainability centres are framed as forming part of the schools' sustainability 'branding' that can help to address increasing demand and pressures to provide a responsible business education.

We're the kind of brand leader, if you like, for responsible business in the school, but we are reflecting what's happening in the school, not reflecting what's happening in one corner of the school... And that's what we're aiming at, I suppose, in that the centre enables the school to achieve certain goals, and we've become the kind of brand leader, if you like, around that responsible business theme. (Centre Head, centre no 2).

Heads of school can point to the work of the sustainability centres to address demands for sustainable business education by students, international initiatives like the PRME, and accreditation bodies. Conversely, sustainability centres can use these demands to justify and legitimise their activities within the school, achieving greater political fit in the course of doing so.

Whilst we have to be careful in generalising trends from our small interview sample, we found some differences in experiences of fit between different geographical locations. In particular, the North American centre heads seem to experience less political fit, whilst in Europe political support seems stronger. European centre heads drew more explicitly on support from external organisations including PRME and accreditation agencies, which they linked to receiving support from their respective deans. These differences are also reflected in membership of the PRME initiative; $34 \%$ of signatories come from Europe, whilst 18\% stem from North America (PRME 2017b).

\section{Interconnections Between Different Types of Fit}

Based on our findings, we theorise that the interconnections between the three types of fit for sustainability centres can be understood as involving legitimacy, resources and collaboration effects (see Fig. 1).

Firstly, the interconnection between technical fit and cultural fit can be understood as involving collaboration effects. Shared values make it easier for colleagues to work together to achieve the integration of sustainable business education, and are strengthened by organisational synergies across a wide array of activities, including teaching in elective and core courses, and research and engagement activities that involve organisational members outside the centre. Moving from left to right at the bottom of Fig. 1, cultural fit entails the existence of shared values between the centre and organisational members, which enhances collaboration on integration of sustainable business education. Centres that have chosen to define sustainable business education in an inclusive way find it easier to collaborate with colleagues, for example, on an increasing number of courses offered to students:

So we've now got an undergraduate pathway and an MSc, but we've also got more elective courses through other MSc programmes. It has increased in profile; that's not helped only by me but also [...] just more people engaged with sustainability and naturally wanting to sort of develop courses around it (Centre Head, centre no 7).

For those centres that have historically developed an isolated position within schools, a lack of cultural fit can be a barrier to achieving technical fit, even if political fit exists. For example, one centre head describes his predecessor's more vocal and critical stance against mainstream management as the 'baggage' he continues to be forced to carry when trying to convince colleagues of the value of integrating sustainability into the core curriculum. Interestingly, this problem persists years after the isolationist strategy was abandoned, despite the centre enjoying good support from the dean:

I'm running around and trying to convince people that we need mandatory courses and not electives. We have made some progress in the past but we definitely need to go one step further. There, I feel, they are really critical whether or not this is a good idea. That I would say is this is baggage I am carrying. (Centre Head, centre no 8).

In this example, the absence of established cultural fit hampers the achievement of technical fit. The strategy chosen to achieve cultural fit, and the resulting (lack of) alignment with the values of organisational members thus 
impacts on the possibility of achieving technical fit. Conversely, when alignment with current organisational structures, capabilities and knowledge can be achieved, there is a positive feedback loop to cultural fit. Moving from right to left at the bottom of Fig. 1, integration of sustainable business education reinforces the impression that values are shared. In schools and universities where structural barriers between different disciplines are low, cooperating on an interdisciplinary subject like sustainability will be more straightforward. This also increases the likelihood that attention to sustainability topics will be given in different courses and activities throughout the school. For example, in schools where structures for interdisciplinary degrees are in place there are likely to be more students that are being exposed to sustainability topics from different perspectives:

A student could bring up in a case discussion or strategy class the environmental or social implications of what they're talking about. And at some schools where this stuff has a small minority of people interested in it or at least identified as being interested in it, the teacher may just say look, let's just move on and there won't be any pushback from the students. But here there is a critical mass [of students] whether a professor likes it or not. He or she is going to have to engage the topic.(Centre Head, centre no 3).

The recursive interconnection between cultural fit and technical fit means that a 'responsive audience' (Centre Head, centre no 3) is created, so that when students bring up a sustainability topic in a course not directly related or managed by sustainability centres, staff will engage with them. On the other hand, it is clear that a tightly defined disciplinary framing by centres may hamper the creation of this positive feedback loop. When wider cultural support is lacking, technical fit may be more difficult to achieve, and consequently sustainable business education may remain a specialised topic in teaching and research activities.

Secondly, the interconnection between cultural fit and political fit can be understood as involving legitimacy effects. Moving upwards on the left side of Fig. 1, approval of organisational members (cultural fit) signals to leaders that their own power will be enhanced by supporting a sustainability centre (political fit). Thus, an additional reason for framing the mission of sustainable business education in an inclusive way, which we found to be the favoured approach of some centres, is that inclusivity can also be used to enhance political fit. In other words, if a sustainability centre manages to align sustainable business education with the prevailing values and beliefs of staff, so that practices become 'enthused in the life of this place' (Centre head, centre no 5), then key organisational actors can derive legitimacy and power by supporting such practices. In one case, the connection between cultural and political fit raised the possibility that a centre could even be held up as an example to other schools:

If we can show how we have been successful in embedding sustainability into the educational life at [our school], maybe that could be an example for other departments around [our university]. (Centre head, centre no 5).

The broader support platform obtained through cultural fit can also mean a more secure future for the centre. The more that colleagues are convinced of the value of sustainable business education, the more likely that a centre devoted to these issues may persist even if political support diminishes due to changes in organisational leaders or their interests and agendas.

Moving down on the left side of Fig. 1, and considering "legitimacy effects" from the other direction, we would argue that support from senior organisational actors (political fit) signals to organisational members that a sustainability centre upholds university-wide shared values (cultural fit). All centre heads we interviewed mentioned either having support from their Dean or using strategic positioning to pursue greater political support, which seems particularly key in the early stages of centre development. Indeed, increasing demands from external stakeholders, including accreditation agencies, for greater emphasis on sustainability topics, enhance the potential to create a positive recursive connection between political fit and cultural fit. Administrators who see sustainability education as an institutional selling point have a clear incentive for highlighting ways in which centres may be a good fit for the existing university culture:

The external environment, changes around PRME and also the accreditation bodies - EQUIS for example has got something about ensuring sustainability related issues are on the curriculum - and AQUIS, AMBA; so all of that I've kind of ruthlessly used to help promote sustainability in the school (Centre head, centre no 7).

Political support, reinforced by messages from external organisations such as accreditation agencies about the value of sustainable business education, may thus convince colleagues that the topic should be taken seriously. However, given the great degree of autonomy of business school faculty (Rasche and Gilbert 2015, p. 244), this is not always the case. For example, one centre head recounts how she had secured the support of the dean of education for integrating a course in the core bachelor programmes. However, the colleagues in charge of the programmes still refused: 'they did not want to be messed around by being told from the top to do something differently' (Centre Head, centre no 9). Clearly, whilst political fit may create favourable conditions for cultural fit, the latter does not follow automatically from 
the former. Rather, significant efforts need to be made in order to convince colleagues and overcome resistance.

Thirdly, the interconnection between technical fit and political fit can be understood as involving resource effects. Moving downwards on the right side of Fig. 1, political support provides resources to enhance technical fit. Political fit, which ensures support from key organisational actors, generally ensures that resources are provided to undertake sustainable business education activities, including centre start-up costs, and support for research and teaching. Centres may be set up through external (private) grants, endowments or funded chair positions, which will all require political support. Sustainability centres often choose to set up specialist teaching programmes as a first step. Moving beyond those specialised programmes often requires another input of political support and associated resources:

We've got to figure out a way to impact more students, touch more students, we've got to find a way for all the MBAs coming out of this building to be exposed to sustainability. The reach and the throw have to be bigger and it can't stay in this programme or it will die. But that has a very political element to it that you've got to get the rest of the School to go along with that expansion and you've got to find a donor who wants to kick in for that. (Centre Head, centre no 3).

Conversely, moving upwards on the right side of Fig. 1, technical fit can provide additional resources to achieve political fit. This is because, once technical fit is established, sustainable business education activities may enhance the 'brand' of the school as a key player in sustainable business education. Integration of sustainable business education throughout the curriculum, for example, ensures that deans can 'walk their talk' regarding sustainability topics (Rasche and Gilbert 2015). In an environment of rising demand, such a position can help attract additional funding, students and other sources of income for the school as a whole.

The two-way direction of the interconnections between the three types of fit suggests that a mutually reinforcing cycle can be created in an ideal scenario. None of the centre representatives we spoke to felt confident that a complete alignment was established in all three areas of fit. However in those centres where a good degree of fit existed in two or more areas, or where active efforts were made to work towards fit in more than one area, there was a clearer sense of the purpose and future viability of sustainability centres. In these cases, directors felt that these centres had a purpose that transcended the individuals associated with them, so that future political headwinds such as a lack of interest from senior management could be countered: 'I can't imagine that the centre would be disbanded; it's hard to imagine what reason there could be for that' (Centre Head, centre no 2). Conversely, those centres which experienced a severe lack of fit in one area, or a pronounced lack of fit in two or more areas, felt more vulnerable to potential future changes in programme structures, agendas of senior management or turn-over of staff associated with the centre.

\section{Discussion and Conclusion}

In response to calls for a better understanding of the organisational and strategic dynamics that guide business school sustainability integration (e.g. Hommel and Thomas 2014), this article examines how sustainability centres achieve technical, cultural and political fit between sustainable business education practices and their internal environment. Our conceptualisation draws on the literature on fit (Ansari et al. 2010 ) and the literature on institutional work (Lawrence and Suddaby 2006). In doing so, we provide insights into the consequences of the three types of fit for the integration of sustainable business education and provide a dynamic conceptualisation of fit. In this section, we first discuss the significance of our findings in each of these areas. We close by considering the underlying question of the desirability of integration with respect to sustainable business education.

We build on the multidimensional idea of fit (Zajac et al. 2000; Venkatraman 1989) to provide a detailed analysis of the strategies for achieving fit in sustainable business education. Our findings suggest that achieving political fit represents a top-down forceful approach to integration. If political fit exists in the absence of cultural and technical fit, the result can be superficial or symbolic implementation of sustainable business education practices. Such a superficial implementation of sustainability education can damage the reputation of business schools if and when it is exposed. By extension, centres that do not frame their approach strategically may lack political support from others in the school and the university, and therefore have access to limited resources. An absence of powerful patrons in turn could inhibit attempts to create better cooperation across the school by 'sharing the gold' (Centre head, centre no 6). In comparison to political fit, achieving cultural fit requires a much more cooperative approach to the integration of sustainable business education. To the extent that cultural fit is not achieved, this can lead to isolation of sustainable business education practices due to a lack of buy-in from organisational constituents. The result may be a temporary approach that disappears if and when key proponents of sustainable business education move to other institutions. Moreover, a lack of cultural fit means it will be difficult to cooperate, for example, in core curriculum teaching or in joint research activities, even when the resources and political support exist. Finally, achieving technical fit is an approach that favours 'bricolage' (Lawrence and Suddaby 2006) of 
existing structures and new practices. In other words, in order to achieve technical fit, successful centres introduce novel networks and programmes that draw on existing university structures as well as introducing new elements. When technical fit is not achieved, these newly developed structures may not work optimally. For example, sustainability education may become isolated, resulting in siloed ways of working, the potential duplication of efforts and wastage of resources. In the absence of technical fit, reinforcement of values becomes more difficult, and creating an integrated approach that can become the 'brand' of a school will be less effective. In sum, different types of misfit lead to distinct problems that in turn give rise to distinctive integration and organisational consequences.

Based on our findings, we note the importance of examining these elements and barriers separately, as well as taking a further step of analysing how and whether the challenges are interrelated. In doing so, we provide an explanation for why political fit (e.g. support from deans) alone need not have sufficient relevance or force in the long term in the absence of some level of technical and/or cultural fit. Future research must thus focus in more detail on elements of cultural integration, technical alignment and the interconnections between these and political fit in sustainable business education. Taking the technical and cultural fit elements of integration more seriously in sustainable business guidance documents and monitoring, evaluation and accreditation mechanisms, along with an appropriate school-level flexibility, can go some way to addressing concerns about superficial or merely symbolic integration of sustainability business education. The challenge, of course, will be that much of this work will be school-specific and difficult to inform from above or by external institutions.

When examining political, technical and cultural fit simultaneously, it becomes clear that the tensions between the different requirements posed by the three areas of fit form a source of dynamism that, to our knowledge, has received little attention in the literature on fit until now. For example, a practice that is tightly defined, with clear boundaries and associated roles and responsibilities, may be attractive to practice experts within organisations, but fail to attract alignment with the identity, values and norms of broader organisational constituents, defined as cultural fit. One consequence of a lack of cultural fit could be that only a narrow technical fit can be achieved, with limited linkages to wider structures and integration into practices that span the organisation as a whole. Conversely, both political and cultural fit seem to be necessary conditions for achieving the goal of broad technical fit. In this case, cultural fit is often achieved through inclusive framing of the practice, which incorporates the many interests of organisational constituents without a clear demarcation of boundaries and rules surrounding membership. Political fit in turn works as a precondition to technical fit insofar as a minimum threshold of hierarchical support and access to resources can transform isolated efforts towards achieving institutional bricolage.

Thus, when examining the three areas of fit simultaneously, the strategies that are employed may run counter to those identified in the literature for each individual type of fit. For example, clear definitions of practices and demarcation of the 'right' to speak on a particular issue (Lawrence and Suddaby 2006) may be a sufficient condition for achieving cultural fit but not a necessary one. This in turn suggests that a holistic perspective of fit has implications for research and practice, which might be overlooked when focussing on an individual aspect of fit in isolation. Further research might explore such implications not just for sustainability centres but for other academic centres, such as those that focus on entrepreneurship (Zahra et al. 2011). This line of inquiry could examine, for example, whether barriers to integration stem mainly from the specific topic or institutional form of sustainability centres or are related to the broader phenomenon of centres in higher education (Stahler and Tash 1994). Further research could also examine the integration of sustainability practices in other types of settings, for example, in responsible investment practices, where this topic has been actively debated (OECD 2017).

Whilst the traditional perspective on fit assumes a positive relationship with performance, dissenting voices highlight the need for misfit in order to foster innovation and radical change (Voelpel et al. 2006). It is clear from our findings that sustainability centres that are focused on achieving fit with their internal environment do not generally seek radical change. Rather, their focus is on incremental change through social suasion and small steps towards integration. They take the current state of business education as given, whilst promoting incremental change from within current structures and practices. Even centres that had historically taken a more critical or even radical stance have recognised the need for integration of sustainability topics into the core curriculum taught in business schools in order to achieve a critical mass of students and gain access to resources. Furthermore, those centre directors that perceived a lack of fit (whether unintentional or purposefully created) between their centres and their business schools, felt more vulnerable to future developments that could impair their current achievements, such as the departure of key staff or a change in political support.

"Is" does not imply "ought", however, and our findings leave open the question of whether sustainable business education might be better served by an approach to integration that emphasises the importance of pressing for genuinely transformative change (Benn et al. 2014). Partisans of this position might see centres as falling short, were they to settle for anything less than a complete re-evaluation of business school values, mission and practices. Indeed, whilst initiatives such as PRME directly call for integration as a 
straightforward positive agenda, others disagree on the merits of integration. Evans et al. (2006, p. 279) note, for instance, that integration is difficult to monitor, whilst the danger exists that students may receive only fragmented approaches instead of an overarching ethical perspective.

On a still more fundamental level, it can be argued that the radical nature of the idea of sustainability, and the existential environmental and social problems that today's business students must consider, are not necessarily well served when centres prioritise 'fitting in' over 'standing up' for a unique point of view (Sharma and Hart 2014). Theorists writing in this vein might caution that current work-such as the present paper - on sustainability education risks smuggling in the normative premise that fit is a feasible and desirable goal for sustainability centres. Once this premise has been accepted, researchers might simply fail to consider whether business schools-by virtue of their service to, and to an extent their dependency upon, the private sector-are even capable of supporting research, pedagogy and advocacy around sustainability in a more than superficial way (for a recent broadside see Conn 2018).

In light of these kinds of concerns, the question might well be asked: What are the appropriate strategies for sustainability centres in business schools whose technical, cultural and political orientations are simply antithetical to sustainability, and are therefore, in some sense, 'beyond fit'? It might be conjectured that such circumstances are unlikely to occur frequently, as business schools would presumably not facilitate the formation of sustainability centres if there were no anticipation of some sort of fit. But it is also true that business schools and universities change, and not necessarily in the direction of becoming more amenable to the concept of sustainability. In such a situation, where the overarching institutional environment appears 'beyond fit', what should the leadership of sustainability centres do?

Given the nature of our data, it is beyond the scope of this paper to offer a definite answer to the question of whether pressing for radical transformation, as opposed to fit-friendly incremental evolution, may represent a more suitable goal for sustainability centres operating within distinctly nonideal institutional conditions. Future research might find it productive to purposively sample successful sustainability actors who are more radical in their outlook, in particular those responding to academic structures that seem 'beyond fit', in order to understand the leadership skills necessary to achieve political, cultural and technical fit without compromising essential values. Or, future studies might look at leadership strategies that permit centres to avoid having to achieve fit in the service of transformative change. ${ }^{7}$

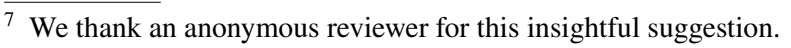

But we would also submit that the contemporary leadership literature may already, within touchstone debates on "transformational" and "transactional" leadership, offer important conceptual tools for addressing this dilemma (Burns 1978; Bass 1985). Transformational and transactional leadership have sometimes been portrayed as opposites, the former involving a visionary re-setting of frameworks and norms, the latter focused more on managing followers in pursuit of near-term organisational goals ( $\mathrm{Du}$ et al. 2013; Waldeman et al. 2006). Where sustainability centres are concerned, however, we would point to research that shows that transformational and transactional strategies can support one other, within the same organisation and even the same individual director. Bass, for instance, argues that transformational and transactional do not represent opposing ends of a continuum, and are instead exhibited simultaneously by the best leaders (1985). In Rao and Sivakumar's (1999) investigation of the establishment of investor relations departments in leading corporations, the transformational (what the authors term 'coercive') strategies of presenting new frameworks for investor rights were conducted by social movements. These radical demands were then made to 'fit' the otherwise resistant corporations by finance professionals using metrics of organisational and managerial performance more characteristic of conventional transactional methods. And Davis and White's (2015) advice to business students who want to be more effective change agents within the corporate world is essentially to bring social movement strategies inside the organisation. They write: 'Reading the organization's climate to know when the time was right for an innovation, using language and stories that positively disposed people toward the idea, recruiting the right allies and avoiding blockers, and using forums that allowed the group to work together effectively, were common to both [social movements and the corporate world]' (Davis and White 2015).

What emerges from studies such as these is the notion that even in the most invidious circumstances, sustainability centres may find ways of exploiting 'beyond fit' demands on business schools, by designing responses that enable ambitious sustainability agendas to serve the organisations' institutional objectives. This hybrid approach does not deny the possibility of circumstances that appear 'beyond fit'. Rather it suggests that recognising and diagnosing 'non-fit'-in particular, where the existing impacts and purposes of business schools seem to beg wholesale re-thinking-may nonetheless be complemented by searches for 'fit'. This can be true even for institutional environments where sustainability, like other radical social innovations, may seem a distant hope.

As sustainability centres grow and become more successful in carrying out their research and teaching aspirations in business schools, it may be argued that their raison d'être is disappearing. According to this line of argument (Baxter 
2012; Mohin 2012), one mark of successful integration might be for sustainability centres themselves to disappear. However, whilst educators might work themselves out of a job if their sole concern were embedding and legitimising sustainability within business schools, the barriers to legitimising sustainability outside universities are even more challenging. Given the myriad global sustainability issues faced by external stakeholders such as corporations, NGOs and governments, it seems certain that sustainability centreseven and perhaps especially in situations that appear 'beyond fit' - will have important work to do for many years to come.

Acknowledgements We thank the editor and two anonymous reviewers for their comments and feedback, and to Eric Guthie for some literature suggestions. We are grateful to the International Centre for Corporate Social Responsibility, Nottingham University Business School, particularly for supporting the initial survey. We also acknowledge the support of Chelsea Hicks-Webster of the Network for Business Sustainability, for assistance in compiling the original database of sustainability centres. Finally, we are grateful for the colleagues who completed the questionnaire and especially for those who also provided interviews.

\section{Compliance with Ethical Standards}

Conflict of interest All authors declares that they have no conflict of interest.

Ethical Approval All procedures performed in studies involving human participants were in accordance with the ethical standards of the institutional and/or national research committee and with the 1964 Helsinki Declaration and its later amendments or comparable ethical standards.

Informed Consent Informed consent was obtained from all individual participants included in the study.

Open Access This article is distributed under the terms of the Creative Commons Attribution 4.0 International License (http://creativeco mmons.org/licenses/by/4.0/), which permits unrestricted use, distribution, and reproduction in any medium, provided you give appropriate credit to the original author(s) and the source, provide a link to the Creative Commons license, and indicate if changes were made.

\section{Appendix: Copy of the Survey}

1. What is your name, centre title, founding date?

2. Source of initiative to create the centre (recognising that the initiative may have had more than one source, please tick the appropriate number of boxes)

3. Purpose of centre (i.e. aims) (please indicate as many purposes as possible)

4. Please indicate which of the following are core and secondary activities of your centre (please indicate as many core and secondary activities as appropriate)

5. Is the director a member of academic, administrative staff or other?
6. How many full time equivalent (FTE) staff does your centre employ?

7. How many academic staff are affiliated, but not employed, by your centre?

8. What is your disciplinary focus? (please indicate as many focuses as appropriate)

9. We intend through interviews to gain more fine-grained insights into the strategies that centres have adopted and the factors that have contributed to their successes. Would you, the director, or a colleague be prepared to participate in a 30-min interview to build more rounded case study of your centre?

\section{References}

Academy of Business in Society \& European Foundation for Management Development (ABIS \& EFMD). 2013. Global deans and faculty survey. Brussels, Belgium: ABIS and EFMD. Retrieved 4 November, 2017, from https://www.efmd.org/index.php/blog/ view/489-abis-efmd-global-deans-and-faculty-survey.

Akrivou, K., \& Bradbury-Huang, H. (2015). Educating integrated catalysts: Transforming business schools toward ethics and sustainability. Academy of Management Learning \& Education, 14(2), 222-240.

Andrews, K. R. (1971). The concept of corporate strategy. Homewood: Irwin.

Ansari, S., Reinecke, J., \& Spaan, A. (2014). How are practices made to vary? Managing practice adaptation in a multinational corporation. Organization Studies, 35(9), 1313-1341.

Ansari, S. M., Fiss, P. C., \& Zajac, E. J. (2010). Made to fit: How practices vary as they diffuse. Academy of Management Review, 35(1), 67-92.

Association of MBAs (AMBA). 2015. Criteria for the accreditation of MBA programmes. London, England: AMBA. Retrieved 4 November, 2017, from http://www.mbaworld.com/ /media/Files /Accreditation/MBA-criteria-for-accreditation.ashx.

Association to Advance Collegiate Schools of Business (AACSB). 2015. Ethics and sustainability resource center. Retrieved 4 November, 2017, from http://www.aacsb.edu/resources/ethic s-sustainability/faq.asp.

Banerjee, S. B. (2011). Embedding sustainability across the organization: A critical perspective. Academy of Management Learning \& Education, 10(4), 719-731.

Bass, B. M. (1985). Leadership and performance beyond expectations. New York: Free Press.

Baxter, L. 2012. Putting yourself "out of business:" The role of a sustainability coordinator. The Whitehouse Blog. Retrieved 4 November, 2017, from https://www.whitehouse.gov/blog/2012/04/25/ putting-yourself-out-business-role-sustainability-coordinator.

Benn, S., \& Dunphy, D. (2009). Action research as an approach to integrating sustainability into MBA programs: An exploratory study. Journal of Management Education, 33(3), 276-295.

Benn, S., Dunphy, D., \& Griffiths, A. (2014). Organizational change for corporate sustainability. London: Routledge.

Benn, S., \& Martin, A. (2010). Learning and change for sustainability reconsidered: A role for boundary objects. Academy of Management Learning \& Education, 9(3), 397-412.

Brunsson, N. (2002). The organization of hypocrisy. Copenhagen: Copenhagen Business School Press.

Burns, J. M. G. (1978). Leadership. New York: Harper and Row. 
Canato, A., Ravasi, D., \& Phillips, N. (2013). Coerced practice implementation in cases of low cultural fit: Cultural change and practice adaptation during the implementation of six sigma at 3M. Academy of Management Journal, 56(6), 1724-1753.

Charmaz, K. (2006). Constructing grounded theory: A practical guide through qualitative analysis. London: SAGE.

Christensen, L. J., Peirce, E., Hartman, L. P., Hoffman, W. M., \& Carrier, J. (2007). Ethics, CSR, and sustainability education in the Financial Times top 50 global business schools: Baseline data and future research directions. Journal of Business Ethics, 73(4), 347-368.

Conn, S. 2018. Business schools have no business in the university. The Chronicle of Higher Education, February 20. Retrieved February, 2018, from https://www.chronicle.com/article/Business-SchoolsHave-No/242563.

Davis, G. F., \& White, C. J. (2015). Changing your company from the inside out: A guide for social entrepreneurs. Boston: Harvard Business Review Press.

Doherty, B., Meehan, J., \& Richards, A. (2015). The business case and barriers for responsible management education in business. Journal of Management Development, 34(1), 34-60.

Drazin, R., \& Van de Ven, A. H. (1985). Alternative forms of fit in contingency theory. Administrative Science Quarterly, 30(4), 514-539.

Du, S., Swaen, V., Lindgreen, A., \& Sen, S. (2013). The roles of leadership styles in CSR. Journal of Business Ethics, 114, 155-169.

Etzkowitz, H., \& Kemelgor, C. (1998). The role of research centres in the collectivisation of academic science. Minerva, 36(3), 271-288.

European Quality Improvement System (EQUIS). 2015. Standards \& Criteria. Retrieved 4 November, 2017, from https://www.efmd. org/images/stories/efmd/EQUIS/2015/EQUIS_Standards_and_ Criteria.pdf.

Evans, J. M., Treviño, L. K., \& Weaver, G. R. (2006). Who's in the ethics driver's seat? Factors influencing ethics in the MBA curriculum. Academy of Management Learning \& Education, 5(3), 278-293.

Friga, P. N., Bettis, R. A., \& Sullivan, R. S. (2003). Changes in graduate management education and new business school strategies for the 21 st century. Academy of Management Learning \& Education, 2(3), 233-249.

Giacalone, R. A., \& Thompson, K. R. (2006). Business ethics and social responsibility education: Shifting the worldview. Academy of Management Learning \& Education, 5(3), 266-277.

Glaser, B. G., \& Strauss, A. L. (1967). The discovery of grounded theory: Strategies for qualitative research. Hawthorn: Aldine de Gruyter.

Godemann, J., Haertle, J., Herzig, C., \& Moon, J. (2014). United Nations supported principles for responsible management education: Purpose, progress and prospects. Journal of Cleaner Production, 62, 16-23.

Godemann, J., Herzig, C., Moon, J., \& Powell, A. 2011. Integrating sustainability into business schools-analysis of 100 UN PRME sharing information on progress (SIP) reports. International Centre for Corporate Social Responsibility Research Paper Series, (58-2011).

Hadorn, G. H., Biber-Klemm, S., Grossenbacher-Mansuy, W., Hoffmann-Riem, H., Joye, D., Pohl, C., Wiesmann, U., \& Zemp, E. (Eds.). (2008). The emergence of transdisciplinarity as a form of research. In Handbook of transdisciplinary research (pp. 19-39). Springer, Dordrecht.

Hommel, U., \& Thomas, H. (2014). Research on business schools: Themes, conjectures, and future directions. In A. M. Pettigrew, E. Cornuel \& U. Hommel (Eds.), The institutional development of business schools (pp. 6-35). Oxford: Oxford University Press.
Jamali, D., \& Abdallah, H. (2015). Mainstreaming corporate social responsibility at the core of the business school curriculum. In D. E. Palmer (Ed.), Handbook of research on business ethics and corporate responsibilities (pp. 275-296). Hershey: IGI Global.

Kaplan, R. S., \& Norton, D. P. (2006). Alignment: Using the balanced scorecard to create corporate synergies. Boston: Harvard Business Press.

Lawrence, T. B., \& Suddaby, R. (2006). 1.6 Institutions and institutional work. In S. R. Clegg, C. Hardy \& W. R. Nord (Eds.), The sage handbook of organization studies (Vol. 2, pp. 215-254). London: Sage Publications.

Maloni, M. J., Smith, S. D., \& Napshin, S. (2012). A methodology for building faculty support for the United Nations Principles for Responsible Management Education. Journal of Management Education, 36(6), 312-336.

Mangematin, V., \& Baden-Fuller, C. (2008). Global contests in the production of business knowledge: Regional centres and individual business schools. Long Range Planning, 41(1), 117-139.

Matten, D., \& Moon, J. (2004). Corporate social responsibility education in Europe. Journal of Business Ethics, 54(4), 323-337.

Miles, R. E., \& Snow, C. C. (1978). Organization strategy, structure and process. New York: McGraw-Hill.

Mohin, T. 2012. Defining success for a "CSR Professional": Driving yourself out of a job? CSR Wire. Retrieved 4 November, 2017, from http://www.csrwire.com/blog/posts/512-defining-successfor-a-csr-professional-driving-yourself-out-of-a-job.

Moon, J., \& Orlitzky, M. (2011). Corporate social responsibility and sustainability education: A trans-Atlantic comparison. Journal of Management \& Organization, 17, 583-604.

OECD. 2017. Investment governance and the integration of environmental, social and governance factors. Retrieved 4 November, 2017, from https://www.oecd.org/finance/Investment-Governance -Integration-ESG-Factors.pdf.

Orlitzky, M., \& Moon, J. (2010). Corporate social responsibility education in Europe: Trends and comparisons. In D. Swanson (Ed.), Toward assessing business ethics education (pp. 143-176). Charlotte: Information Age Publishing.

Perkmann, M., \& Spicer, A. (2008). How are management fashions institutionalized? The role of institutional work. Human Relations, 61(6), 811-844

Principles for Responsible Management Education (PRME). 2012. Inspirational guide for the implementation of PRME: Placing sustainability at the heart of management education. Retrieved 4 November, 2017, from http://www.gseresearch.com/uploads/files /pdf/prme/FINAL_COMPLETE.pdf.

Principles for Responsible Management Education (PRME). 2015. 'About the initiative' Academic, business and government leaders worldwide to identify best practices for integrating sustainability and responsibility into business education. Retrieved 4 November, 2017, from http://www.unprme.org/news/index.php?newsid=359.

Principles for Responsible Management Education (PRME). 2017a. Policy on sharing information on progress. Retrieved 4 November, 2017, from http://www.unprme.org/reporting/sip-policy.php.

Principles for Responsible Management Education (PRME). 2017b. SIP recognitions and PRME pioneers announced, July 24. Retrieved 4 November, 2017, from http://www.unprme.org/news/ index.php?day $=24 \&$ month $=7 \&$ year $=2017$.

Rao, H., \& Sivakumar, K. (1999). Institutional sources of boundaryspanning structures: The establishment of investor relations departments in the Fortune 500 industrials. Organization Science, 10(1), 27-42.

Rasche, A., \& Gilbert, D. U. (2015). Decoupling responsible management education: Why business schools may not walk their talk. Journal of Management Inquiry, 24(3), 239-252. 
Rasche, A., Gilbert, D. U., \& Schedel, I. (2013). Cross-disciplinary ethics education in MBA programs: Rhetoric or reality? Academy of Management Learning \& Education, 12(1), 71-85.

Rusinko, C. A. (2010). Integrating sustainability in management and business education: A matrix approach. Academy of Management Learning \& Education, 9(3), 507-519.

Sharma, S., \& Hart, S. L. (2014). Beyond "saddle bag" sustainability for business education. Organization \& Environment, 27(1), $10-15$.

Snelson-Powell, A., Grosvold, J., \& Millington, A. (2016). Business school legitimacy and the challenge of sustainability: A fuzzy set analysis of institutional decoupling. Academy of Management, Learning and Education, 15(4), 703-723.

Solitander, N., Fougère, M., Sobczak, A., \& Herlin, H. (2012). We are the champions: Organizational learning and change for responsible management education. Journal of Management Education, 36(3), 337-363.

Stahler, G. J., \& Tash, W. R. (1994). Centers and institutes in the research university: Issues, problems, and prospects. The Journal of Higher Education, 65(5), 540-554.

Starik, M., Rands, G., Marcus, A. A., \& Clark, T. S. (2010). From the guest editors: In search of sustainability in management education. Academy of Management Learning \& Education, 9(3), 377-383.
Suddaby, R., \& Greenwood, R. (2001). Colonizing knowledge: Commodification as a dynamic of jurisdictional expansion in professional service firms. Human Relations, 54(7), 933-953.

Venkatraman, N. (1989). The concept of fit in strategy research: Toward verbal and statistical correspondence. Academy of Management Review, 14(3), 423-444.

Voelpel, S. C., Leibold, M., \& Tekie, E. B. (2006). Managing purposeful organizational misfit: Exploring the nature of industry and organizational misfit to enable strategic change. Journal of Change Management, 6(3), 257-276.

Waldeman, D. A., Siegel, D. S., \& Javidan, M. (2006). Components of CEO transformational leadership and corporate social responsibility. Journal of Management Studies, 43, 8.

Weber, K., \& Weager, D. (2017). Organizations as polities: An open systems perspective. Academy of Management Annals, 11(2), 886-918.

Zahra, S. A., Newey, L. R., \& Shaver, J. M. (2011). Academic advisory boards' contributions to education and learning: Lessons from entrepreneurship centers. Academy of Management Learning \& Education, 10(1), 113-129.

Zajac, E. J., Kraatz, M. S., \& Bresser, R. K. (2000). Modeling the dynamics of strategic fit: A normative approach to strategic change. Strategic Management Journal, 21(4), 429-453. 